\title{
Morphometric Characteristics and the Relation of Stream Orders to Hydraulic Parameters of River Goro: An Ephemeral River in Dire-dawa, Ethiopia
}

\author{
Girma Moges*, Vijaya Bhole \\ University College of Sciences, Department of Geography and Geo-informatics, Osmania University, India
}

Copyright ( 2015 Horizon Research Publishing. All rights reserved.

\begin{abstract}
Major morphometric parameters of Goro watershed were derived from Aster Global Digital Elevation Model (GDEM) using ArcGIS10.1 extension, Arc Hydro Tool 2.0 in order to characterize it quantitatively. The study also assessed the relation of stream orders to selected channel hydraulic parameters (width, depth, channel bed slope, velocity and discharge) at bankfull flow condition. Channel geometry data and grain size samples collected from 14 representative cross-sections used as input to compute hydraulic parameters using equations appropriate for ungauged streams. The analysis of morphometric parameters indicate that pattern of stream networks is less controlled by structural condition though the area is situated in the rim of the great east African rift valley; and its geomorphic development is at late youth stage. Though hydraulic components of the channel do have a positive relation with stream orders, only channel cross-section area and discharge well related to stream orders [each increased at the rate of 0.86 and 1 on average with $\mathrm{R}^{2}$ of 0.92 and 0.8 respectively with increasing in stream orders]. However, depth, velocity and bed slope of the channel are less explained by stream order, which may indicate us these hydraulic parameters are rather affected by other local channel factors.
\end{abstract}

Keywords Ephemeral Stream, River Goro, Morphometric Parameters, Hydraulic Parameters, GIS

\section{Introduction}

Ephemeral rivers are major geomorphic agents in designing and carving the landforms in arid and semi-arid areas. Though these rivers flow over substantial areas of the world, where many people live, they are little studied compared with perennial rivers [1]. Ephemeral rivers are less studied because most of them located relatively remote places where usually difficult to reach them. For this reason, the geomorphic processes, hydraulic characteristics and sediment transport of most ephemeral rivers are not well studied so far in order to predict their behavior [2].

Geomorphologists may follow different approaches in studying the geomorphology of a river system. A river system is classified in to three: "Morphological (form) system, cascading (process) system and process-response system" [3]. The first system mainly stress on relation of the forms in a river system. Forinstance, we may relate the arrangement of stream patterns with upstream slope within the system. Morphometric and statistical analysis are the most widely used methods in this approach. Morphometric parameters are mainly classified in to linear, areal and relief parameters.

Quantitative analysis of morphometric parameters helps us to understand geologic structure that may control the river system in a watershed, the situation of recent diastrophic activities and its geomorphic history [4]. Most studies on watershed morphometric analysis use the result to compare different watersheds by relating linear and aerial morphometric parameters to stream orders. Number of streams and stream order show an inverse linear relationship with small deviation from straight line when the logarithm of the number of streams plotted against stream order. Stream orders also relate logarithmically with stream length and drainage area [5]. The amount of water and sediment, discharge in a stream network related with the drainage area over which stream networks drain. The amount of discharge that passes over a cross-section has power relation with other channel variables or hydraulic parameters such as width, depth, velocity, slope, roughness factor and sediment load. Therefore, there must be a certain relation between stream orders and these hydraulic parameters because of the fact that (1) streams with various orders do have their own hydraulic characteristics. These characteristics have an impact on the hydraulics of the channel with different orders, especially when we see the issue from upstream to downstream. (2) Stream order do have a certain relation with the drainage area so that they should have a relation with discharge and with other variables that have power relation with discharge such as channel width, depth, velocity and 
slope. Leopold and Miller [6] explained the relation of drainage networks to hydraulic parameters using logarithmic functions (equation 1-4) that relate stream orders to width, depth, bed slope and discharge of channels. The relation of each hydraulic parameters produce straight line when plotted on a semi-log paper against stream order.

$$
\begin{aligned}
& u=k \log w \\
& u=k \log d \\
& u=k \log S \\
& u=k \log Q
\end{aligned}
$$

Where, $u=$ stream order; $w=$ bankfull channel width; $d=$ bankfull channel depth; $S=$ channel bed slope and $Q=$ bankfull discharge.

There are few researches on the morphometric characteristics of ephemeral streams in general and no study has been so far done on its morphometric characteristics of river Goro in particular. Most of the downstream section the study river is situated in in the urban area, Dire-Dawa town, which is frequently affected by sudden, powerful, flash flooding. Flood protection and mitigation practices on the channel require knowledge of its morphometric characteristics and hydraulic behaviors. This study will serve as a database for those who want to further study to see the influence of change in watershed morphometric parameters on the hydraulics and channel processes of the main channel through time and space in any efforts to undertake channel and watershed management.

The two main objectives of this study includes 1) describe the watershed based on the quantitative analysis of linear and areal morphometric parameters of river Goro. 2) To quantitatively explain the relation of stream orders to the selected hydraulic parameters.

\section{Materials and Methods}

\subsection{Study Area}

Goro Watershed is found in Dire-Dawa administration, Ethiopia. The longitude and latitude extent of the watershed (as per the result of watershed delineation), is between $9.44^{\circ}$ and $9.63^{\circ} \mathrm{N}$ and $41.78^{\circ}$ and $41.88^{\circ} \mathrm{E}$. The study watershed is assumed to inherit the climate of the Dire-Dawa administration, in which the watershed is found. The administration experiences with desert and semi-desert climate. Though it exhibits small seasonal variation, the temperature is hot throughout the year and progressively increases as one goes to northward. The high temperature may be attributed to climate with mean annual daily value of bright sunshine which equals to 8 hours. The mean annual average air temperature is $25.3^{\circ} \mathrm{C}$. June is the warmest month of the year whereas December and January are the coldest. The area receives seasonal rainfall with a bimodal distribution that peaks in April and August. The two seasons are spring and summer (locally knowns as 'Belg' and keremet respectively) in which the area receives about $80 \%$ of the annual rainfall separated by a short dry spell in June. The mean annual rainfall of the administration is $657 \mathrm{~mm}$. The

\begin{tabular}{|c|c|c|c|c|}
\hline Category & Parameter & Formula & Adopted from & Value \\
\hline \multirow{6}{*}{ Linear } & Stream length $(\mathrm{Lu})$ & length of a stream & Horton [5] & \\
\hline & Mean stream length (MSL)* & $\mathrm{Lu} / \mathrm{Nu}$ & Strahler [4] & \\
\hline & Stream Length ratio (RL)* & $\mathrm{RL}=\mathrm{X}(\mathrm{w}+1) / \mathrm{X}(\mathrm{u})$ & Dingman[10] & \\
\hline & Bifurcation ratio(RB)* & $\mathrm{Rb}=\mathrm{N}(\mathrm{u}) / \mathrm{N}(\mathrm{u}+1)$ & Dingman [10] & \\
\hline & Average bifurcation ratio (ARB) & average $\mathrm{RB}$ of all orders & Schumn [11] & 1.44 \\
\hline & Length of overland flow (Lg) & $1 / \mathrm{DD} * 2$ & Horton [5] & 0.68 \\
\hline \multirow{7}{*}{ Areal } & Drainage density (DD) & $\Sigma \mathrm{X} / \mathrm{AD}$ & Dingman [10] & 0.73 \\
\hline & Stream frequency (SF) & $\mathrm{Nu} / \mathrm{AD}$ & Horton [12] & 0.44 \\
\hline & Drainage texture (DT) & $\mathrm{Nu} / \mathrm{P}$ & Horton [5] & 0.38 \\
\hline & Drainage area ratio $(\mathrm{RA})^{*}$ & $\mathrm{RA}=\mathrm{AD}(\mathrm{u}+1) / \mathrm{AD}(\mathrm{u})$ & Dingman $[10]$ & \\
\hline & Form factor $(\mathrm{Ff})$ & $\mathrm{AD} / \mathrm{Lb}^{2}$ & Horton [12] & 0.20 \\
\hline & Circularity ratio (CR) & $4 * \mathrm{Pi} * \mathrm{AD} / \mathrm{P}^{2}$ & Miller [13] & 0.11 \\
\hline & Elongation ratio $(\mathrm{Re})$ & $(\mathrm{AD} / \mathrm{pi})^{1 / 2} / \mathrm{Lb}$ & Schumn [11] & 0.25 \\
\hline Relief & Relief ratio (Rh) & $\mathrm{H} / \mathrm{Lb}$ & Schumn [11] & 0.05 \\
\hline
\end{tabular}
mean monthly rainfall values vary between $5.7 \mathrm{~mm}$ in December and $119 \mathrm{~mm}$ in April [7].

Table 1. Adopted formulae and values of some morphometric parameters for River Goro

Note: Except few parameters, many computed by using Arc hydro tool. Values of Parameters. Symbols defined as:

$\mathrm{Lu}=$ total stream length of order ' $\mathrm{u}$ '

$X(u)=$ average length of streams of order " $u$ "

$\mathrm{N}(\mathrm{u})=$ number of stream of order $\mathrm{u}$

$\mathrm{DD}=$ drainage density

$\mathrm{Nu}=$ Total no. of streams of all orders

$\mathrm{Nu}=$ Total number of streams of all orders

$\mathrm{AD}(\mathrm{u})=$ average drainage area of stream of order ' $\mathrm{u}$ '

$\mathrm{Lb}=$ basin length

$\mathrm{Pi}=3.14$

$\mathrm{Pi}=3.14$,
$\mathrm{Nu}=$ total number of stream segments of order ' $\mathrm{u}$ '

$X(u+1)=$ average length of the next higher order stream

$\mathrm{N}(\mathrm{u}+1)=$ number of stream of the next higher order

$\mathrm{X}=$ total length of stream draining the area

$\mathrm{AD}=$ Area of the basin

$\mathrm{P}=$ Basin Perimeter,

$\mathrm{AD}(\mathrm{u}+1)=$ average drainage area of the next higher stream order

$\mathrm{Lb}^{2}=$ square of basin length

$\mathrm{P}^{2}=$ square of the perimeter

$\mathrm{H}=$ Total (Relative) relief of the basin, 


\subsection{Morphometric Data}

Data required to analyze drainage networks extracted from Aster Global Digital Elevation Model (GDEM) version-2 with resolution $30 \mathrm{~m}$. The GDEM of the study area was freely downloaded from NASA website [8] for October 2011 since GDEM is not available for times after the specified month and year to use the recent data. Then ArcGIS10.1 with Arc Hydro Tools version 2.0 used to process the data, delineate the watershed of River Goro and perform drainage network analysis. All morphometric parameters calculated for this study are indicated in (Table 1).

The threshold value of the flow accumulation raster is very essential to determine the number of stream features to be included in a watershed which affects morphometric parameters because the determination of the orders of rivers depends on the first stream in a watershed. In other words the values of stream order we assign on a map highly depends on the scale of representation of the stream features on the map. It is recommended to use $1 \%$ of the maximum value of the flow accumulation raster as a threshold value of stream representation during watershed delineation using DEM [9]. For this research, the threshold value was determined based on the field experience, Google earth observation and professional judgment to avoid the inclusion of pseudo streams. Finally, the value $1300(1.4 \%)$ of the maximum flow accumulation raster was used as the threshold value. Area and length parameters were automatically calculated using the ArcMap10.1 after stream orders are assigned based on Strahler's method of stream ordering [4]. Strahler's method of stream ordering was used only to characterize the watershed interms of morphometric parameters. Shreve's method of stream ordering was applied to relate stream orders with hydraulic parameters because this methods capable us to include lower order streams which we usually ignore when we use Strahler's method of stream ordering. That means, if we follow Strahler's method we may omit lower order streams when we go to downstream so that it will significantly affects the hydraulic and hydrologic processes of the channel. Moreover, experts of the area advice to use Shreve's method of stream ordering for any analysis in a watershed involving runoff and rainfall parameters (which are directly or indirectly related to hydraulics of a channel). However, because of shortage of finance and time, parameters such as slope, width and depth of the channel were not measured for all orders of stream networks in Goro watershed. Measurements were taken from 14 cross-section sites following the main channel through the longest possible flow line and one tributary (Figure 1). Velocity and discharge were estimated for each sites using empirical questions for ungauged river channel like Goro since there is no other option to estimate flow parameters to be related to the orders of streams. The detail of methods used to determine hydraulic parameters is presented in the next section.

Geological data of the study watershed were taken from Geological survey of Ethiopia in the form of hard copied map which later scanned and georeferenced to digitize the fault lines of the study area. The digitized fault line features were then mapped together with channel networks to qualitatively explain their interaction.

\subsection{Data for Hydraulic Parameters}

Since Goro has no any measured data to compute flow and hydraulic parameters required for this study, channel survey was undertaken in October, 2013 to determine cross-sectional area, flow depth, hydraulic radius, channel bed slope and discharge at bankfull flow. The preliminary identification of cross-section sites using Google earth, topo-maps and aerial photos was substantiated by field observations. According to the research need and aim, the researcher started from a fixed point upstream from where the first cross-section ( $\mathrm{x} 01)$ was measured. Then measurement site for the next cross sections was determined at interval equivalent to 10 widths of the first (previous) cross-section downstream. A total of 14 cross-sections were surveyed (Figure 1) using Total Station. Major criteria used to identify a cross-section site were reach with no or little obstruction on the river bed, devoid of tributary junctions, clear slope change between the flood plain and the channel (if the flood plain exists on measuring site) and reach where the channel is straight enough to take Total station readings downstream and upstream from the center of a reach.

As it was observed from the Google earth map and confirmed during field observation the second zone of the river is more sinuous. In such cases only few cross-sections at straight sites were selected to avoid complications in meander geometry. Many researchers stressed that the field identification of bankfull stages of ephemeral streams based on their geomorphic set up is usually difficult since the definition given to bankfull stage is not consistent. Identification of flow at bankfull stage is complex and varies according to the relative height of the river bed in relation to the height of the surrounding major depositional landforms like flood plain, channel benches and levees. Researchers proposed varies methods to identify bankfull flow stage in a channel. It is possible to use the marked change in slope between the flood plain and the channel to clearly delineate the bankfull stage if the cross-section site found undisturbed. In cross-section sites where floodplain surfaces broken up or obstructed by "floods chutes, chute bars, high sandy levees and zones of stripping", bankfull stage can be defined from the average height of channel banks via the reach, ignoring significant flood effects [14]. Moreover, defining bankfull stage for a channel cross-section may be difficult in situations when: 1) the stream has wide, flat bed, 2) its bank appears as vertically with poor cohesive materials, 3) absence of channel vegetation to identify bankfull stage based on the scar of the last flood. In addition to the previous stated methods, reconstruction of "collapsed bank materials" may give clues of bankfull channel stage for a channel with collapsed bank [2]. 


\section{Stream Networks of Goro ordered according to Shreve's Method}

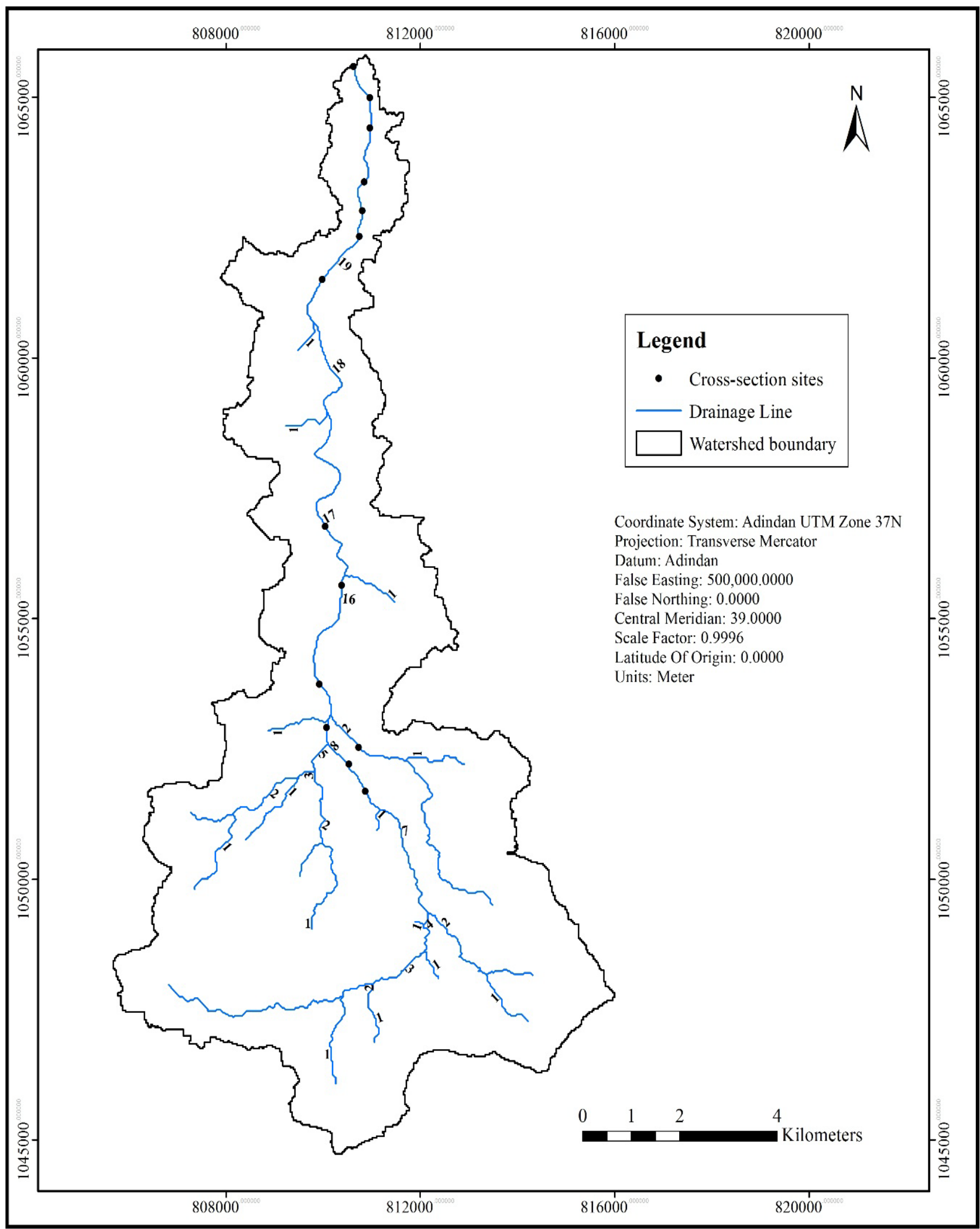

Figure 1. Stream order (Shreve's method) and Cross-section sites in the River Goro 
As a result, bankfull flow stages for the study cross-sections were identified based on the methods proposed above and some additional methods wherever appropriate for the cross-section sites to measure the required morphologic data. The Total Station was installed at the center of the reach where the reader can clearly view reflectors both at the downstream and upstream of the cross-section cutline. The maximum reach length for most of the surveyed reach set to 500 meter. Four surveyors from the Department of Surveying, in Institute of Technology, Dire-Dawa University, participated in the field survey.

As indicated by (equations 9 -11) $\mathrm{D}_{50} . \mathrm{D}_{84}$ and $\mathrm{D}_{90}$ are required to determine average flow velocity. For this reason, bed material samples were taken $10-20 \mathrm{~m}$ upstream of the cross-section line to avoid sediment trampling and alteration while measuring the cross-section. This proposed method is the most appropriate to select sites of sediment sampling in the cross-section according to the geomorphological and sedimentological characteristic of the study river and the aims of the research as confirmed by other authors that have worked on similar river (Billi, personal communication). Volumetric sampling was preferred to other methods of grain size sampling to avoid bias for the most upper sediment grains. An iron cup with 10 centimeters height and 8 centimeters radius used to grab the grain samples up to $0.5 \mathrm{~cm}$ depth from the surface of the channel bed. The specific sample sites were identified based on the occurrence of homogeneous grain sizes through visual inspection. Three samples with equal volume collected from a quarter right, the middle and a quarter left of a cross-section following straight line across the channel. Later the three samples were mixed to bring one representative composite sample for a cross-section in the main channel. Thus a total of 14 composite samples were taken to laboratory for grain size analysis.

Each composite sample exposed to sample splitter and conning and quartering to gain 200 grams of sieve sample with representative grains of all possible sizes for finial sieving. A 200 gram sample taken from the composite samples dry sieved using a standard set of sieves (specified as STD ISO 3310, BS410) arranged on one (1) phi scale ranging from $4 \mathrm{Phi}$ (finer) to $-4 \mathrm{Phi}$ ( the coarser). Sieves arranged on half (0.5) phi provide more accurate result than those arranged on one phi. However, it was not possible to sieve at the interval of $1 / 2$ phi because of the absence of sieves with diameter that equals with phi value of 0.5 (positive and negative), $1.5,2.5$ and 3.5 . Then sieves arranged on Ro-Tap (mechanical shaker with timer) in descending order of mesh size and exposed for shaking for 10 minutes until the grains separately retained on each sieves according to their size. The materials retained on each sieve and on the bottom pan weighed using a balance with sensitivity of 0.1 gram. The weight of material or sediment in each size fraction and the proportion of sample that was lost during sieving were determined. Finally, $\mathrm{D}_{50}$, and $\mathrm{D}_{84}$ and $\mathrm{D}_{90}$ estimated using the graphical method (based on lognormal distribution) after drawing cumulative frequency curve of percentage grain size retained on each sieves for each samples in phi units.

Channelbed slope, bankfull width, average bankfull depth (assumed equal to hydraulic radius) and bankfull channel cross-sectional area were calculated using coordinates and elevation data measured at the field. Assuming steady uniform flow conditions, the mean flow velocity was calculated using Che'zy's equation [15].

$$
V=C(R S)^{0.5}
$$

where, $\mathrm{V}=$ mean flow velocity $(\mathrm{m} / \mathrm{s}), \mathrm{C}=$ channel roughness constant, $\mathrm{R}=$ the hydraulic radius $(\mathrm{m}), \mathrm{S}=$ energy slope assumed parallel and equal to the gradient of the bed $(\mathrm{m} / \mathrm{m})$. The constant $\mathrm{C}$ is proportional to the Darcy-Weisbach friction factor ' $f$ 'and written as follows where, $g$ is the acceleration due to gravity $\left(9.81 \mathrm{~ms}^{-2}\right)$.

$$
C=\frac{(8 g)^{0.5}}{f^{0.5}}
$$

There are many equations used to calculate ' $f$ ' as reported from literatures. However, many of those equations did not specifically address the conditions of ephemeral streams. The following equations used in this study to estimate the value of ' $\mathrm{f}$ ' and flow velocity (in SI units). Then the average value of the results was used to calculate other flow parameters. Though it is was not tested for its applicability for ephemeral stream, Equation 7 was selected for this study because it uses channel depth and channelbed slope both of which are the most important determinants of flow velocity. Equation 8 and Equation 9 were selected because they originally developed for sand bed streams. The selection of Equation 10 is because of its applicability for gravel and sand bed streams [15]. Moreover, Thomson and Cambell equation was used since the equation predicted velocity values closer to measured data of Gereb Oda River, an ephemeral river found in North Eastern part of Ethiopia [16].

$$
\begin{aligned}
& V=10.8 d^{0.67} S^{0.33} \quad \text { (Lacey) } \\
& f^{-0.5}=0.696(S)^{-0.256} \quad \text { (Bray) } \\
& V=(g d S)^{0.5} 4.8\left(d / D_{50}\right)^{0.11} \text { (Grant) } \\
& f^{-0.5}=0.82 \log \left(4.35 R / D_{84}\right) \text { (knighton) } \\
& f=\left[\left(1-\left[\frac{0.1 k_{s}}{d}\right]\right) 2 \log \left(\frac{12 d}{k_{s}}\right)\right]^{-2} \text { (Thomson \& Cambel,) }
\end{aligned}
$$

where, $\mathrm{f}=$ the Darcy-Weisbach roughness coefficient; $\mathrm{d}=$ mean flow depth or channel depth $(\mathrm{m}) ; \mathrm{S}=$ channel bed slope $(\mathrm{m} / \mathrm{m}) ; \mathrm{g}=$ gravity $\left(9.81 \mathrm{~m} / \mathrm{s}^{2}\right) ; \mathrm{R}=$ hydraulic radius $(\mathrm{m}) ; \mathrm{D}_{50}$ $=$ grain size for which $50 \%$ of the grain size distribution is finer $(\mathrm{mm}) ; \mathrm{D}_{84}=$ grain size for which $84 \%$ of the grain size distribution is finer $(\mathrm{mm})$; and $\mathrm{k}_{\mathrm{s}}=$ Nikuradse roughness length $\left(2 \mathrm{D}_{90}\right)$.

Finally, discharge at each cross-sections was estimated using the continuity equation as indicated below where, $\mathrm{Q}=$ bankfull discharge $\left(\mathrm{m}^{3} / \mathrm{s}\right) ; \quad A=$ Bankfull channel cross-sectional area $\left(\mathrm{m}^{2}\right)$.

$$
\mathrm{Q}=\mathrm{AV}
$$




\section{Result and Discussion}

\subsection{Drainage Network of River Goro: Pattern and Characteristics}

The type of stream pattern for River Goro identified is dendritic, which is the characteristics of many natural rivers (Figure 2). This pattern is usually common in areas where little geological (folding and faulting) controls on the channels. The main trunk of river is more sinuous in most its middle reach where less resistant rock deposit, the recent alluvium, intercalated with upper Paleozoic deposits. Consequently, river Goro, opts for less resistant rock layer ignoring upper Paleozoic rock deposits (which are comparatively more resistant to erosion) and alternate its route according to the pattern of less resistant rocks of recent ages (recent alluvium and recent and Pleistocene alluvium). From the same map, the recent alluvium observed sandwiched with Pleistocene alluvium in most part of lower reach.

Table 2. Areal coverage of major rocks in Goro watershed

\begin{tabular}{cccc}
\hline No. & Formation Era & $\begin{array}{c}\text { Area } \\
\text { coverage } \\
\left(\mathrm{km}^{2}\right)\end{array}$ & $\begin{array}{c}\text { Percent Area } \\
\text { Covered }\end{array}$ \\
\hline 1 & $\begin{array}{c}\text { Recent Alluvium } \\
\text { Recent and Pleistocene }\end{array}$ & 4.03 & 4.77 \\
2 & alluvium & 3.77 & 4.46 \\
3 & Pleistocene to recent & 0.32 & 0.38 \\
4 & Holocene & 0.1 & 0.12 \\
5 & Upper Paleozoic & 35.13 & 41.54 \\
6 & Precambrian & 41.22 & 48.74 \\
\hline
\end{tabular}

Rocks formed during the Precambrian era share majority of the watershed area followed by the upper Paleozoic rocks each cover $48.7 \%$ and $41.54 \%$ of the total area of the watershed respectively (Table 2). These two types of rock are major parent source of sediment for the river Goro. The presence of rock fractures and fault lines are widely accepted as the major controlling factors of channel initiations and valley developments at the early stages of channel formation. However, Figure 1 shows the presence of many streams over the oldest rock crossing the fault lines and only few of them follow the line of fractures and fault lines. This may indicate us most streams had achieved well developed routes before they were influenced by fractures and fault lines during their early development. This clearly indicates us channel formation is older than the start of tectonic activities (like faulting and folding) in the area. Had tectonism been the older phenomenon, at least many of the should aligned with the fracture lines since early channels prefer to follow fracture lines. From this, we can safely conclude that the pattern of channels in the study area is more controlled by the variation in rock resistances than the presence of fault lines.

Tectonic and geological influence on channel patterns of the study watershed was quantitatively checked using bifurcation ratio (RB). Many researchers used bifurcation ratio (RB) to compare and explain the geological controls over the arrangement of streams in basins. RB is the ratio of the number of streams in a given order to the number of streams in the next higher order [11]. In a watershed where the geological setting do not distorted the pattern of its stream, the value of RB ranges between 3 and 5 [4]. In other words, the value of RB shows small variation for different environments and different regions unless the geological controls (like faulting and folding) dominant. So it is relatively powerful parameter to find out hints about the influence of structural controls over the pattern of streams. With respect to hydrology and fluvial geomorphology, determination of RB has also a profound importance to assess the potential extent of flooding and channel-forming discharge since RB tells us about the extent of streams branching. In a basin with more branched streams, flow is less concentrated so that flooding is not that much a threat. However, watershed with less number of bifurcated streams would probably cause flooding to an area; and erosion and transportation are the most dominant fluvial geomorphic processes expected in the watershed.

Table 3. Bifurcation ratio, stream length, and drainage area ratio for each stream orders of River Goro.

\begin{tabular}{cccccccc}
\hline $\mathrm{u}$ & $\mathrm{N}(\mathrm{u})$ & $\mathrm{RB}$ & $\mathrm{Lu}$ & $\mathrm{MSL}$ & $\mathrm{RL}$ & ADA & $\mathrm{RA}$ \\
\hline 1 & 19 & 2.11 & 29.87 & 1.57 & 0.78 & 2.64 & 3.93 \\
2 & 9 & 3 & 11.01 & 1.22 & 1.37 & 10.39 & 2.14 \\
3 & 3 & 0.5 & 5.02 & 1.67 & 1.61 & 22.28 & 2.83 \\
4 & 6 & & 16.22 & 2.70 & & 63.16 & \\
\hline Sum & 37 & 5.61 & & & 3.76 & & 8.91 \\
Average & 1.87 & & & 1.25 & & 2.97 \\
GA & & 3.7 & & & 2.55 & & 4.55 \\
\hline
\end{tabular}

Note: $\mathrm{u}=$ stream order, $\mathrm{N}(\mathrm{u})=$ number of stream of order ' $\mathrm{u}$ ', $\mathrm{Lu}=$ Total stream length of order ' $u$ ', MSL = mean stream length, RL stream length ratio, $\mathrm{ADA}=$ average drainage area, $\mathrm{RA}=$ drainage area ratio and $\mathrm{GA}=$ global average taken from Dingman, 2009. .

In the study watershed, Goro, the value of RB between first order and second order, between second and third order and between third and fourth order streams is $2.11,3$ and 0.5 respectively with an average value of RB 1.87 for the whole watershed, which is nearly twice less than the global average value (Table 3). However, it is usual to use the weighted mean $\mathrm{RB}$ value to characterize a watershed using more representative value in situation when the values of $\mathrm{RB}$ differs for sequential stream orders. For this reason, the weighted mean RB of the study watershed was calculated as follows.

$$
W R B=\frac{R B_{1} N\left(u_{1}\right)+R B_{2} N\left(u_{2}\right)+R B_{3} N\left(u_{3}\right)}{\text { Total number of stream segments }}
$$

Where,

WRB $=$ Weighted mean bifurcation ratio

$\mathrm{RB}_{1}=$ bifurcation ratio between $1^{\text {st }}$ and $2^{\text {nd }}$ order

$\mathrm{RB}_{2}=$ bifurcation ratio between $2^{\text {nd }}$ and $3^{\text {rd }}$ order

$\mathrm{RB}_{3}=$ bifurcation ratio between $3^{\text {rd }}$ and $4^{\text {th }}$ order

$\mathrm{N}\left(\mathrm{u}_{1}\right)=$ total number of streams involved in $\mathrm{RB}_{1}$ computation; $\mathrm{N}\left(\mathrm{u}_{2}\right)=$ total number of streams involved in $\mathrm{RB}_{2}$ computation; $\mathrm{N}\left(\mathrm{u}_{3}\right)=$ total number of streams involved in $\mathrm{RB}_{3}$ computation. 
Drainage, Faultlines and Geological deposits

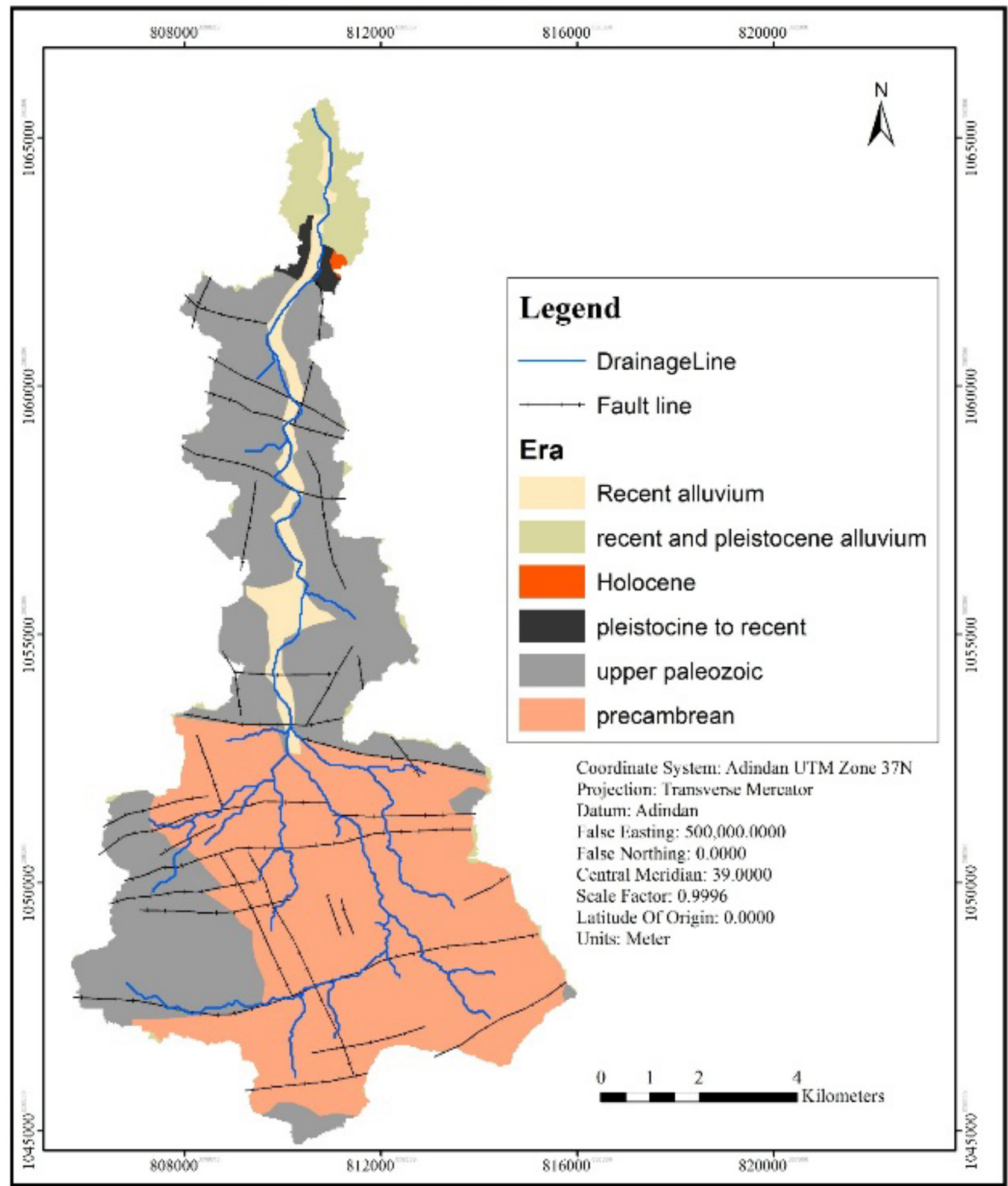

Figure 2. Drainage pattern, fault lines and bed rocks of Goro watershed. Fault lines and rock types digitized from the geological map prepared by Ethiopian Institute of Geological Surveys, Ministry of Mines, Energy and Water Resources (1985). Flow direction is towards North. 
The weighted mean bifurcation ratio (WRB) for the watershed of Goro is 2.7. The value of WRB which is less than the range between 3 and 5 , indicates that geological structures (tectonic activity) exert very low influence on the pattern of streams as confirmed by $[4,17]$. Therefore, from the value of WRB, we can say that the pattern and arrangements of channels in Goro watershed less affected by geological structures though the watershed is located in the rim of great African Rift valley, which is widely believed as one of the world most tectonically active areas.

\subsection{Stream Orders}

In this study, Goro is found as fourth order streams based on the output of the Arc Hydro tool 2.0. This is because the watershed was delineated from the small area with relatively larger scale. This means the order for the main stream of River Goro would decrease if we decrease the scale of delineation since the main river would have joined the next higher stream order. Therefore, we recommend our readers to bear in mind that the scale of delineation is relatively larger while reading and interpret the interpret stream orders and other morphometric parameters of the study river.

\section{Stream order and number of streams}

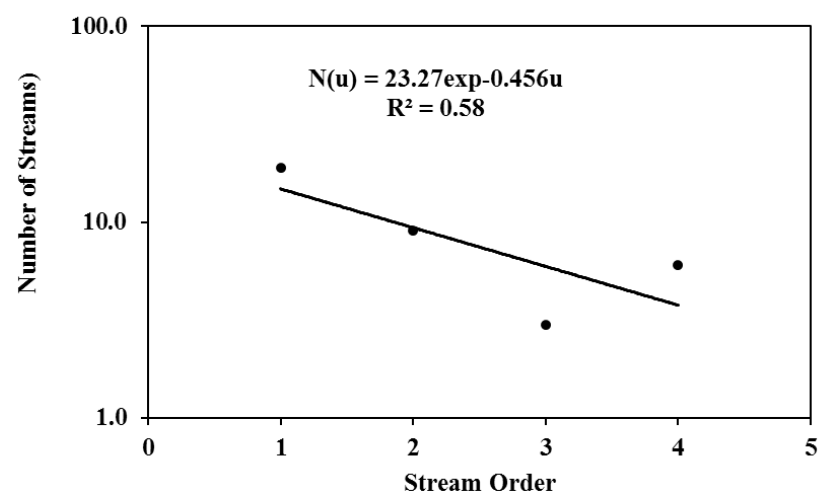

Figure 3. Relationship of number of streams to stream orders

The trunk stream in which water and sediment from the catchment of the study river passes through has an order of four. Most of the streams are first order streams, which account for $51.4 \%$ followed by the second and fourth order streams each representing $24.32 \%$ and $16.22 \%$ of all orders of river Goro. This simply indicated that numbers of orders of streams of the study area decreases downstream, and majority of the first order streams are found in the upper reach. Number of streams and stream order show an inverse linear relationship with small deviation from straight line when the logarithm of the number of streams plotted against stream order [5, 18]. This principle is checked for the case of Goro watershed. The result seems similar with that of Horton's law of Stream numbers" (Figure 3) where the number of streams decreases geometrically at the rate of 0.456 as the order of stream increases; and the number of streams and stream order exhibited well inverse relationship with coefficient of determination $\left(\mathrm{R}^{2}\right)$ greater than 0.6. However, unlike most reckoned, the number of third order streams is less than the number of fourth order streams, which might attributed to the shape of the watershed. As indicated in Figure 4, the watershed goes narrower as we go downstream to the middle and lower reaches with little contributory area on both sides of the main channel. In the middle reach, streams developed from the watershed boundaries and join the fourth order stream as they were first order streams since the relative overland flow is short compared with the areas in the upper reach where the area is wider. Based on Strahler's method of stream ordering, the joining of the first order streams to a fourth order stream doesn't bring change on the order value downstream so that the study watershed exhibited relation of stream number to stream order deviated from the law of stream numbers.

\subsection{Length, Mean Length and Length Ratio of Streams}

The total stream length for first order, second order, third order and fourth order streams is $29.87 \mathrm{~km}, 11.01 \mathrm{~km}, 5.02 \mathrm{~km}$ and $16.22 \mathrm{~km}$ respectively. The total stream length of first ordered streams is by far greater than the second, third and fourth order streams. Generally, the total stream length of respective orders decreases with increasing order of streams though there is deviation at the fourth order streams. This is because most of first order streams and all of second and third order streams are found in the upper reach (Figure 4) of the study watershed where all operate over a homogeneous lithology, Precambrian rock. However, upper Paleozoic and recent alluvium are lithologies of the middle reach where most streams prefer the later lithology, the relatively softest rock, over which mainly the fourth order stream operate surpassing streams with order less than 4 (Figure 2). This situate might led the total length of fourth order stream to deviate from the "law of stream length", which states that the total length of orders of streams decreases with increasing order of stream [5].The other reason is the slope of the watershed. Streams do exhibit longer in their size when the slope of the area over which they drain becomes gentler. As indicated in Figure 5, most of the first order, second order and third order streams drain over a moderate slope area with slope value ranges between $10 \%$ and $25 \%$. Whereas, all segments of the fourth order streams are draining over gently slope area with a value of slope less than $10 \%$ so that fourth order streams travel longer distances than other order streams. Generally, the same figure indicates that stream lengths increases with decreasing in the slope of an area drained from which the fourth order streams of the study area gained an advantage to increase their length.

Drainage network components are associated with basin surface and related to the mean stream length (MSL). The values of mean stream length are depicted in Table 3 and the relation of mean stream length with stream order is presented in Figure 6. The results indicate that mean stream length increases at the rate of 0.194 with increasing order of streams. This relation goes in line with the "law of stream lengths" proposed by (Horton, 1945). 


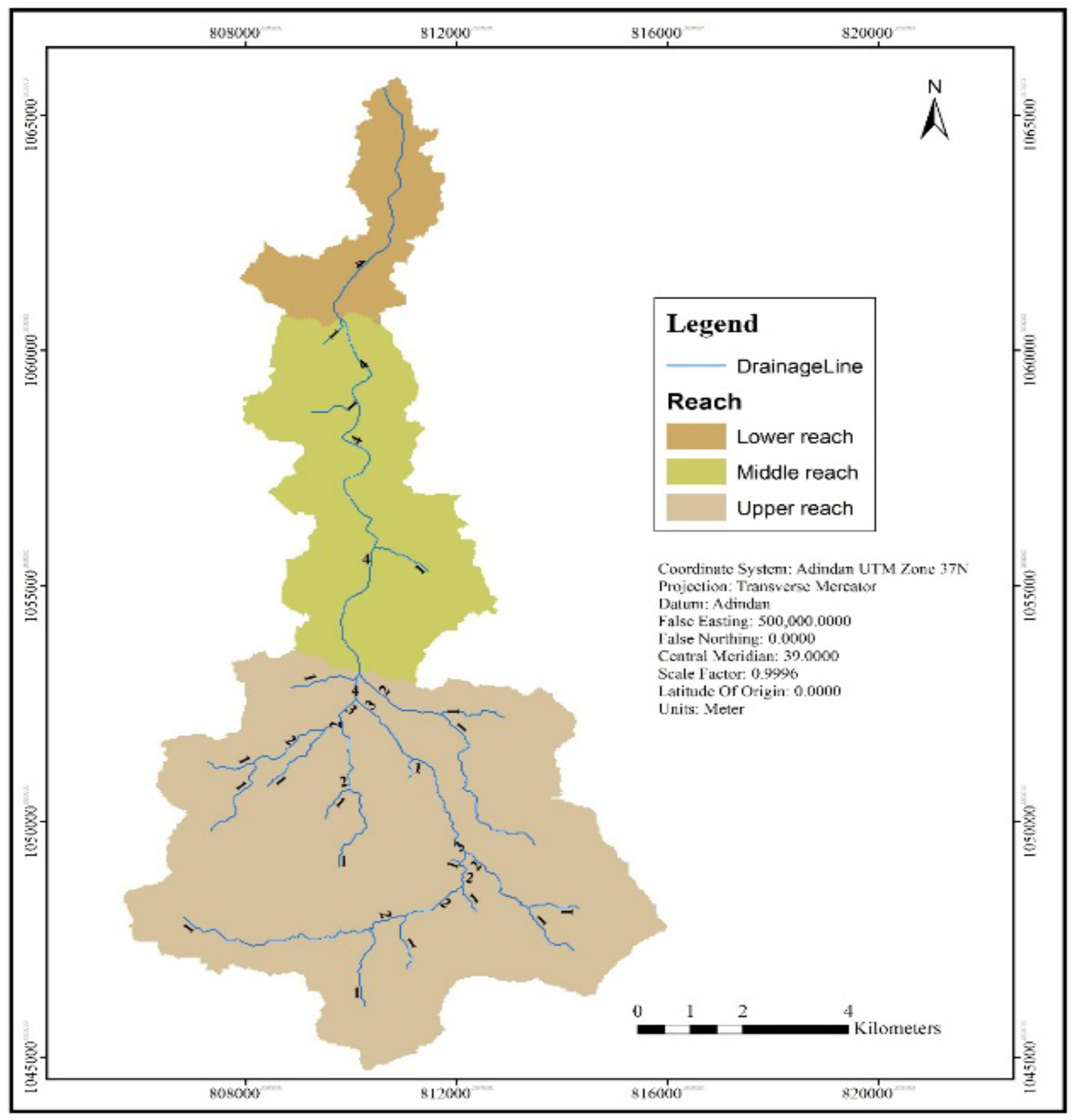

Figure 4. Map of stream orders in the upper, middle and lower reaches of River Goro. Flow direction is towards north. 


\section{Streams orders and Slope in Goro Watershed}

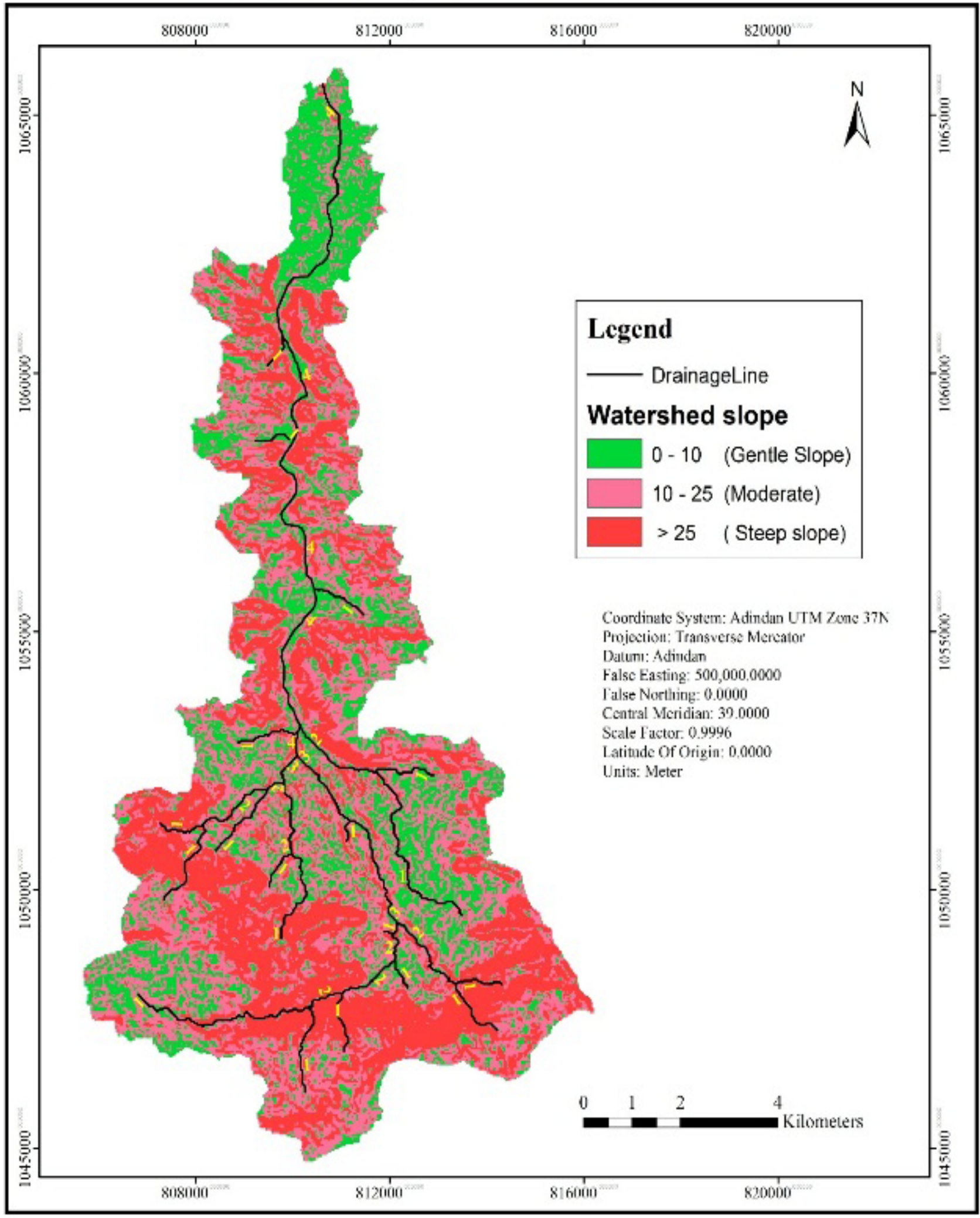

Figure 5. Map of ordered stream segments and slope of the Goro watershed. Slope value is given percent. Flow direction is towards north. 
Stream length ratio (RL) of the study watershed was calculated by dividing the mean length of a stream with specific order to the mean length of the next lower ordered stream. The value ranges between 0.78 and 1.61 whereby the minimum value represents most first order streams from the upper reach of the watershed (Table 3). The other importance of stream length ratio is that it can give us general clue about the stage of the geomorphic evolution of the area. Therefore, the change in the values of stream length downstream indicates us the late youth characterizes the stage of the geomorphic development of the watershed. Consequently, aggradation and valley widening are the most important geomorphic processes expected in the study watershed. During the field survey, it was confirmed that aggradation and valley widening are alternatively dominant than valley deepening in most of the upper reach. In the middle reach of Goro, the river valley is confined by upper Paleozoic rocks exposed on both sides of the main channel. Farther down to the lower reach, the channel is routing over the Bajada land (coalescence of alluvial fans). These merged alluvial fans are the sites where part urban of Dire-Dawa established.

Stream order and mean stream length (MSL)

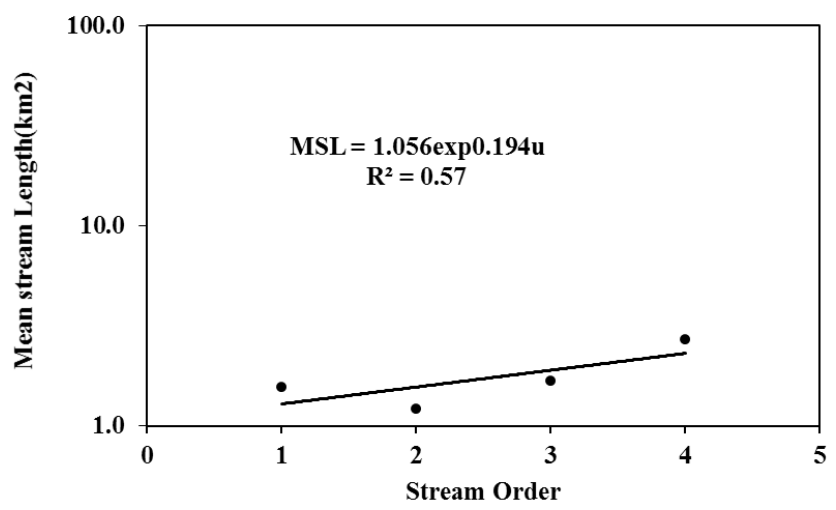

Figure 6. Relation of mean stream length to stream orders

The urban built up and artificial structures situated at the flood plain and the river bank may affect hydraulic and geomorphic processes of the river in its lower reach. The proximity of its lower reach to the urban community exposed the study river to extensive sand harvesting which is widely used for the development of urban infrastructures. Channel scouring is the major geomorphic scar observed in the lower reach of river Goro. The major reasons which might contribute to channel scouring in the lower reach are: 1) the presence of bed rocks (recent and Pleistocene alluvium), which less resistant to erosion compared with rocks in its upper and middle reaches, might ease the flowing water to erode its way. 2) Extensive sand cultivation by the urban community reduces the channel material to be carried away by the flowing water. 3) Channel route of the lower reach is surrounded and confined by the built ups and artificial structures. The built up areas might serve as surfaces impervious to rainfall that probably contributed additional amount of runoff drained to the main channel in the lower reach where the estimated amount of discharge is relatively higher than the middle and upper reaches (see Figure 8f) . The increasing amount of discharge leads to the increase the magnitude of other hydraulic variables (like stream power) relevant to channel scouring. Therefore, interplay of the latter two factors might favored channel scouring in the lower reach of the study river because a confined channel supplied with significant runoff from its surroundings capable to scour its bed where it couldn't access enough sediment to be transported.

\subsection{Drainage Density, Stream Frequency, Drainage Texture and Drainage Area Ratio}

Drainage density (DD) of the watershed is calculated by dividing the total length of streams of all orders by the drainage area of the watershed to indicate the closeness of spaces between channels. In other words, it provides the quantitative value for the average length of all channels for the whole watershed. The DD of Goro watershed is 0.73 $\mathrm{km} / \mathrm{km}^{2}$. Whereas the stream frequency, SF (total number of stream segments in all orders per unit area) of the watershed is 0.44 per $\mathrm{km}^{2}$. The drainage texture, DT (total number of stream segments per perimeters of the watershed area) is 0.38 per $\mathrm{km}$ (Table 1). The DT of Goro watershed falls under coarser category based on Horton's classification [5].

DD, DF and DT mainly affected by the natural factors like climate, rainfall, vegetation cover, rock type, infiltration capacity of the soil, relief and stage of landform evolution $[4,5]$. The spatial distribution and intensity of these factors jointly or independently affects drainage density of a watershed either by increasing the infiltration capacity of the soil or aggravating surface runoff. If areas of the watershed could infiltrate significant amount of the rainwater drainage density, stream frequency and drainage texture would decrease. However, as per field observation, Goro watershed is not densely vegetated rather areas in the upper reach of the river are widely used for agricultural activities and rural settlements. As referred from the geological map, parent material of the soil in the watershed is mainly old aged rocks, and even these rocks seen exposed over wider areas. Of course, it needs detailed investigation on physical soil parameters to speak about the porosity. Nevertheless, what can we exactly deduced from the geological setup of the area is that most of the channels in the watershed are draining over resistant rocks. In addition, nearly $26.6 \%$ of the watershed area has slope greater than $30 \%$, of which majority accounted for the upper reach. The relief of the watershed is $956.05 \mathrm{~m}$ with an average elevation of $1396.45 \mathrm{~m}$.a.s.l, and the minimum and maximum elevation are $1091.05 \mathrm{~m}$ and 2047.10 meters above sea level respectively (Table 4). All these parameters should favor for Goro watershed to have high drainage density and consequently increase the value of stream frequency and stream texture. But the reverse result was found. The reason might be the climate condition of the area, which is semi-arid, that receive little amount of rainfall throughout the year, except in August and April, when the area receives 
maximum rainfall, and hydrologically speaking flooding occurred mostly during these rainfall seasons. As mentioned earlier in the discussion under bifurcation ratio, the streams in the watershed are less bifurcated so that all channels encourage concentrated flow along the already established channels during high rainfall instead of forming new channel that could increase the drainage density and number of stream segments. This situation is also encouraged by the relatively shorter length of longest flow path length $(29.5 \mathrm{~km})$, which is little greater than the basin length of the watershed (Table 4).

Table 4. Some relief parameters of Goro watershed

\begin{tabular}{ccc}
\hline No & Parameters & Value \\
\hline 2 & Average elevation in meter & 1396.45 \\
3 & Relief in meter & 956.05 \\
4 & Maximum elevation in meter & 2047.10 \\
5 & Minimum elevation in meter & 1091.05 \\
6 & Average area slope in percent & 21.48 \\
7 & Percent of area with slope greater than 30\% & 26.46 \\
8 & Elevation at outlet in meter & 1091.05 \\
11 & Relative relief in meter per kilometer & 276.51 \\
16 & Basin length in kilometer & 20.71 \\
\hline
\end{tabular}

Note: variables computed using Arc Hydro Tool, in ArcGIS10.1

Mean drainage area and drainage area ratio are other areal parameters computed for the study area. The mean drainage area for each order of stream is calculated by dividing the total area drained by a given order of the stream to the total number of streams in the same order. The relation of mean basin area to the stream orders shows that drainage area increases at the rate of $0.255\left(\mathrm{R}^{2}=0.93\right)$ with increasing order of streams (Figure 7).

River order and Average drainage area(ADA)

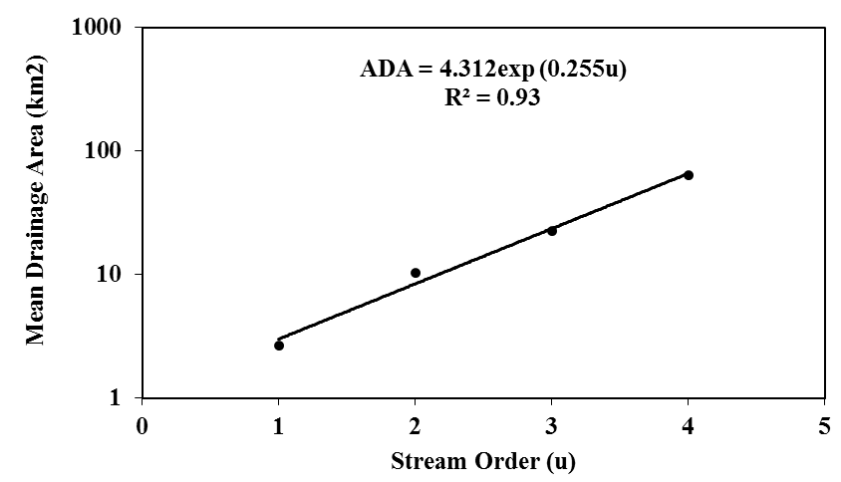

Figure 7. Relation of drainage area to stream orders

This relationship appears similar with the "law of drainage areas" [5]. The drainage area ratio for the study area gradually decreases downstream (Table 3). Similar reason as explained for mean stream length can be applicable.

\subsection{Length of Overland Flow (Lg)}

Half of the reciprocal of drainage density gives us length of overland flow, which tells us about the length of the ground the water flow over it before it gets concentrated into a definite channel. The length of overland flow for the whole watershed is 0.68 (Table 5). However, it was necessary to see the change in length of overland flow $(\mathrm{Lg})$ downstream to see its relation with the average slope of the channel. As indicated in Table 4, length of overland flow ( $\mathrm{Lg}$ ) increases downstream while the average slope of the channel decreases. In other words, length of overland flow inversely related to the average channel slope. This indicates that sheet flow (erosion) is higher in the watershed area that feeds to the upper reach of the main channel compared with the subsequent watersheds areas that contribute flow and sediment to the middle and lower reaches.

Table 5. Length of overland flow and average channel slope in three reaches of River Goro.

\begin{tabular}{cccc}
\hline No & Reach Name & $\operatorname{Lg}$ & $\begin{array}{c}\text { Average } \\
\text { Channel slope } \\
\mathrm{m} / \mathrm{km}\end{array}$ \\
\hline 1 & Upper reach & 0.009 & 1381.02 \\
2 & Middle reach & 0.023 & 960.97 \\
3 & Lower reach & 0.061 & 836.50 \\
\hline
\end{tabular}

Note: Average channel slope is calculated using Arc Hydro tool from the ADEM following the channel center line.

\subsection{Form Factor (Ff), Circulatory Ratio (CR) and Elongation Ratio (Re)}

These parameters involve characterizing the watershed when we want to estimate the shape of the watershed based on their respective quantitative values. The calculated value of Ff, CR and Re for the study watershed is.20, 0.11 and 0.25 respectively (Table 1). Form factor (Ff) characterizes the shape of the watershed based on the ratio of drainage area to basin length. A basin with a value of form factor always greater than 0.78 if its shape is circular, otherwise the shape is said to be elongated [19]. Based on similar assumption, the shape of the study watershed is elongated which means the flow reaches peak flow within relatively longer period. Circulatory (CR) ratio also used to characterize Goro watershed. Its value is determined by taking the ratio of the area of the watershed to the area of the basin having the same circumference as the perimeter of the basin. The value ranges between zero (elongated) and one (circular). Based on this parameter, the shape of Goro watershed is elongated which indicate coarser stream frequency and the watershed is less efficient in collecting the water from the overland area to the main channel that in turn inhibits the amount of discharge (relatively speaking with reference to the expected amount to be collected from the whole area). However the elongation ratio calculated for the area is out of the range values (0.6 1.0) proposed by Schumn [11].

\subsection{Relief Ratio (Rh)}

This term used to express the ratio of maximum relief to horizontal distance along the line of longest dimension parallel to the trunk stream [11]. It generally indicates the overall steepness of a watershed. The relief ratio of the study 
watershed is 0.05 (Table 1) from which we can say that the study area has an overall gentle slope.

\subsection{Relation of Stream Orders and Hydraulic Parameters of River Goro}

In the previous sections, we have seen that stream orders do relate logarithmically with stream length and drainage area. In addition, in the introduction part, we justified that there must be a certain relation between stream orders and hydraulic parameters. Stream orders related with factors of channel hydraulics in the form of logarithmic functions [6]. Logarithmic function was applied to explain the relation between stream orders and channel hydraulic parameters specifically width, depth, cross-section area, channel slope, velocity and discharge. As displayed in (Figure.1), the number of surveyed cross-section does not match with the number of orders of streams. For an order with more than one cross-section, the mean value of each hydraulic variables was used to relate them to stream order.

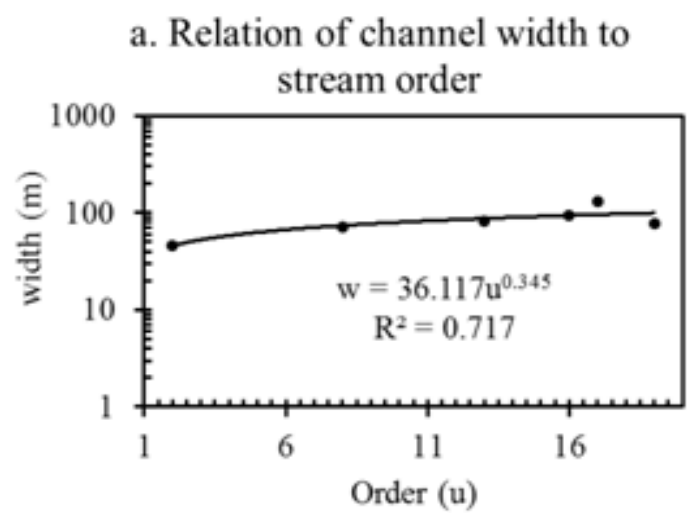

\section{b. Relation of chnnel depth to stream}
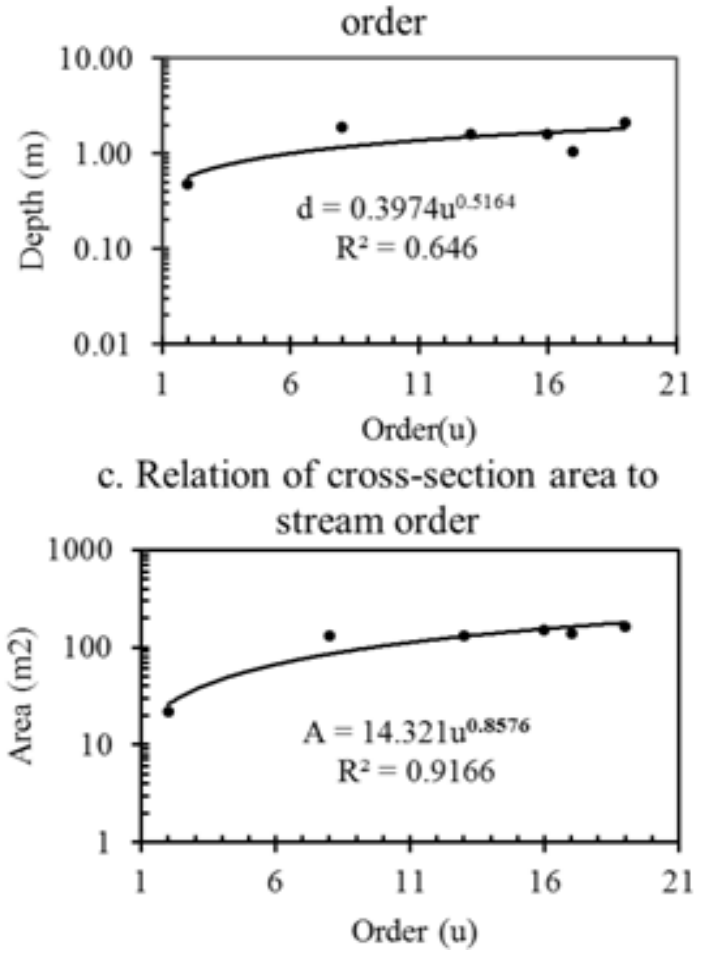
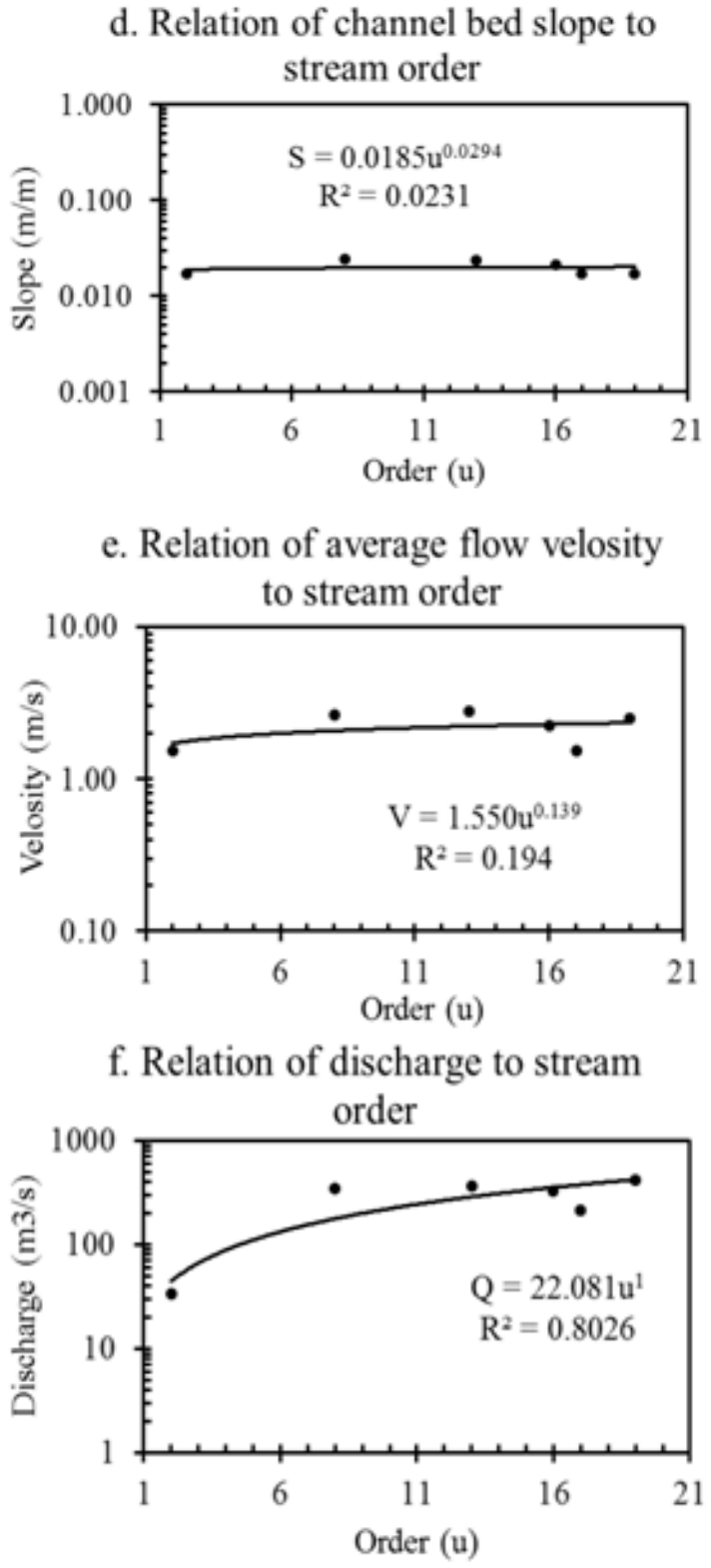

Figure 8. Relation of channel hydraulic parameters to stream orders of River Goro.

Trend lines and power equations drawn from the scatter diagram of the stream orders and channel hydraulic parameters of river Goro using Microsoft Excel. From the available trend line options, power trend found more appropriate than the other type of trend lines since it resulted with higher coefficient of determination $\left(\mathrm{R}^{2}\right)$ when the trend line fitted to the scatter plot of each channel hydraulic variables and stream orders. In addition, Leopold and miller proposed to express the hydraulic parameters in relation to stream orders using exponential or power function [6]. The trend lines and equations (equation $8 a-f$ ) show that all hydraulic components of the channel do have a positive relation with stream orders though there is a considerable scatter deviated from the trend lines that we have to take care of while interpreting the result. Channel cross-section area and discharge well, positively correlated to stream orders as 
it was expected (each increased at the rate of 0.86 and 1 on average with $\mathrm{R}^{2}$ of 0.92 and 0.8 respectively as stream orders increase. The reason is that, as we go downstream from the watershed divide the orders of stream increases and the cumulative area drained by streams increases. The increasing in drainage area results in increasing the amount of discharge downstream. The increasing in discharge would lead the channel to increase its cross-sectional area through channel widening or channel deepening to accommodate the flow influx. This means downstream increasing or decreasing of channel width and channel depth are the results of adjustment, which is indirectly affected by other factors operating at watershed scale or/and channel scale. For this reason, width and depth of channel are less correlated with stream order downstream whereby each changes at the rate of 0.35 and 0.52 . Channelbed slope also shows an increasing trend along with increasing stream order that may result in increasing velocity downstream at the rate of 0.14 . However, the coefficient of determination in the case of channelbed slope and velocity is very low which indicate stream orders of the study area do not well explain the variation of local hydraulic parameters. Forinstance, velocity could be affected by a number of factors such as roughness conditions, hydraulic radius and channel depth. Generally, we can safely say that width, depth and velocity increase downstream of river Goro along with increasing in the order of stream, which goes in comply with the behavior of other ephemeral streams in America studied [6].

\section{Conclusions}

The drainage pattern analysis and average bifurcation area indicates that channel networks in Goro watershed are less controlled by tectonic structures (folding and faulting) though the study area is located in the eastern margin of the rift valley.

Since the study channel (s) prefer less resistance rock for their routes, particularly in the middle and lower reach so that we can say bedrock control is relatively higher than structural control.

Numbers of orders of streams of the study area decreases downstream, and majority of the first order streams are found in the upper reach. The total length of fourth order stream found deviated from the "law of stream length" which states that stream length decreases with increasing stream order because this study found that the length of fourth order stream is greater than the lower order streams.

The late youth stage characterizes the stage of the geomorphic development of the study watershed. Consequently, aggradation and valley widening are the most important geomorphic processes. During the field survey, it is confirmed that aggradation and valley widening are alternatively dominant than valley deepening in most of the upper reach. In the middle of Goro, the river reach valley is confined by the exposed upper Paleozoic rocks on both sides of the main channel. Farther down to the lower reach, the channel is routing over the Bajada land (coalescence of alluvial fans), but confined by urban settlement and artificial structures. This situation coupled with extensive sand exploitation at the channel bed is suggested as one of the major reasons for the study river to exhibit relatively narrower and deeper channel morphology in its lower reach.

All watershed parameters such as slope, bedrock condition and human activities are existing favoring condition for higher drainage density and fine drainage texture in the area, however, the result was the reverse which might be attributed to low stream bifurcation and the climate of the area. Because the area gets its highest rainfall twice a year with shorter period, the watershed couldn't get chance to create new channel that would increase stream frequency, texture and drainage density. In addition, since the watershed has low bifurcation ratio, stream favor flow concentrated along the already formed channels.

The length of overland flow is inversely related to the average channel slope. This indicates that sheet flow (erosion) is higher in the watershed area that feeds to the upper reach of the main channel compared with the subsequent watersheds areas that contribute flow and sediment to the middle and lower reaches.

The relation of stream order to hydraulic parameters of the study river is well explained using power equation with higher $\mathrm{R}^{2}$ than other trend lines. The least square fit of stream order with the channel hydraulic variables indicate that all hydraulic components of the channel do have a positive relation with stream orders though there is a considerable scatter deviated from the trend lines. The correlation of channel cross-section area and discharge to stream orders is higher than the correlation of channel width and depth to stream order (but acceptable correlation). However, the coefficient of determination in the case of channelbed slope and velocity is very low which indicate stream order does not well explain such type of local hydraulic parameters.

Finally, it is recommended to take detail study on the relation of morphometric parameters and channel hydraulic variables taking numerous ephemeral streams, It is also essential to compare ephemeral stream with perennial streams in terms of hydraulic characteristics in connection with morphometric parameters.

\section{Acknowledgements}

Our appreciation goes to all institutions and experts who directly and indirectly helped us to succeed in this research. To mention some of them Dire-Dawa University, Ethiopia; Department of Geography and Geo-informatics, OU, India,; Eskender Ayele and his colleagues in the department of Surveying, DDU, Derese Kumssa, Addis Belete and Prof. Paolo Billi. 


\section{REFERENCES}

[1] UNEP, Status of desertification and implementation of the United Nations plan of action to combat desertification, Report of the executive director, United Nations Environment Program, Nairobi, 1992

[2] Billi Paolo, Morphology and sediment dynamics of ephemeral stream terminal distributary systems in the Kobo Basin (Northern Welo, Ethiopia), Elsevier, Geomorphology, vol.85, pp 98-113, 2007.

[3] Charlton Rosemary, Fundamentals of fluvial Geomorphology, Taylor \& Francis, USA and Canada, 2007.

[4] Strahler, A.N, Quantitative Geomorphology of drainage basin \& channel Networks. In V.T. Chow (ed.), Handbook of Applied Hydrology, McGraw Hill Book Company, New York, 1964.

[5] Horton, R.E, Erosional development of streams and their drainage basins: Hydrological approach to quantitative geomorphology, Bulletin of the Geological Society of America, 56(3), pp 275-370, 1945.

[6] Leopold, L.B, and Miller John.P, Ephemeral streams:-Hydraulic factors and their relation to the drainage net, US Geological Survey Professional paper 282-A, 1956.

[7] Dire Dawa Administrative council Water, Mines and Energy office Dire-Dawa Administrative Council Integrated Resource Development master plan study project by Water Works Design and Supervision Enterprise, Addis Ababa, 2003.

[8] NASA (National Aeronautics and Space Administration), GDEM (Aster Global Digital Elevation Model), Version-2, online available from http://reverb.echo.nasa.gov $/$ reverb/\#utf8=\%E2\%9C\%93\&spatial_map=satellite\&spatial _type $=$ rectangle

[9] ESRI (Environmental System Research Institute), Arc Hydro Tools-Tutorial, version 2.0, New York, USA, 2011.
[10] Dingman S. Lawrence, Fluvial Hydraulics, Oxford University Press, USA, 2009.

[11] Schumn, S.A., Evolution of drainage systems and slopes in Badlands at Perth Amboy, New Jersey. Bulletin. Geological Society if America,.67, pp.597-646, 1956.

[12] Horton, R. E, Drainage basin characteristics, Transactions-American Geophysical Union, 13, pp 350-361, 1932.

[13] Miller, V. C., A quantitative geomorphic study of drainage basin characteristics in the clinch mountain area, Virginia and Tennesse, Project, NR 389-402, Technical Report 3, Columbia University, Departmental of Geology, ONR, New York, 1953.

[14] Kemp Justine, Downstream channel changes on a contracting, anabranching river: The Lachian, Southeastern Australia, Elsevier, Geomorphology, vol-121, No 3-4, pp231-244, 2010.

[15] Billi Paolo, Bedforms and sediment transport processes in the ephemeral streams of Kobo basin, Northern Ethiopia, Elsevier, Catena, vol-75, pp 5-17, 2008,

[16] Billi Paolo, Flash flood sediment transport in a steep sand-bed ephemeral streams. Elsevier, International Journal of Sediment Research, vol.26, No 2, pp1-17, 2011.

[17] Waikar M.L.and Chavadekar Ajay, Investigation on change detection in Chandpur watershed area by using RS and GIS. International Journal of Multidisciplinary and Current Res, vol.2, pp2321-3124, 2014.

[18] Deb Pamela, Morphometric Analysis and its Relation to Tectonics of Upper Chandraprabha River Basin, an International Multidisciplinary Research Journal Vol.2, No.7, 2012.

[19] Singh Vineesha and Singh U.C (2010), Basin morphometry of Maingra River, district Gwalior, Madhya Pradesh, India. International journal of geomatics and geosciences Volume 1, No 4, 2011 